\title{
DONALD TRUMP'S POLITICAL COMMUNICATION ON FACEBOOK - AN ANALYSIS OF THE PRE-ELECTION PERIOD (2020)
}

\section{BRUNO FERREIRA COSTA}

bdfc@ubi.pt

Holder of a PhD in Political Science, University of Lisbon. Researcher at the Praxis - Centre of Philosophy, Politics and Culture (Praxis-UBI). Assistant Professor of the University of Beira Interior, Department of Communication, Philosophy and Politics (Portugal).

\section{Abstract}

The media coverage of electoral campaigns has been reinforced by the massive use of social networks. The impact and dynamics associated with these contents are a unique object of study in the analysis of the political message transmitted by the candidates and in the study of its effectiveness. The digitization of politics and the transformation of traditional electoral campaigns implies the need to reinforce studies on the impact of social media during an election campaign. Using content analysis, in a qualitative and quantitative study, this article aims to address the presence of Donald Trump on Facebook in the last month of the 2020 presidential election campaign. Considering the proliferation of online information, it is important to study the content expressed by the Republican candidate and its impact on his followers. According to the purposes of the research, the expected results will allow us to understand the discursive dynamics and the communication adopted by Donald Trump in this social media, as well as to gauge the reactions to each publication, in a path that mixes the contributions of electoral and political communication studies.

\section{Keywords}

Political communication, Donald Trump; Facebook; US presidential elections; social media.

\section{How to cite this article}

Costa, Bruno Ferreira. Donald Trump's political communication on facebook - an analysis of the pre-election period (2020). Thematic dossier International Relations and Social Networks, July 2021. Consulted [online] on date of last visit, https://doi.org/10.26619/16477251.DT21.8

Article received on January 4, 2021 and accepted for publication on March 21, 2021 


\title{
DONALD TRUMP'S POLITICAL COMMUNICATION ON FACEBOOK - AN ANALYSIS OF THE PRE-ELECTION PERIOD (2020) ${ }^{1}$
}

\author{
BRUNO FERREIRA COSTA
}

\section{Introduction}

The approach to the presidential elections in the United States of America is one of the determining paths to understand the international political system and existing political communication forms. The emphasis given by the international media to this electoral process, as well as the impact of US foreign policy on the global order, constitute core aspects to understand the various political phenomena, as well as governance models at a supranational scale.

Likewise, communication strategies are a relevant source of analysis of existing trends in terms of the preparation and handling of electoral campaigns on a global comparative scale.

The study of leaderships has been based on a strengthening of the relationship between the political agenda, the media agenda and the way political actors seek to convey their message to the electorate. In this context, there is a significant change in the means and in the way of communicating, corresponding to a paradigm shift regarding traditional electoral campaigns.

The emergence of political leaders outside the traditional axis of the "party leadership" and other media stages, such as the world of television, the world of entertainment or business deals, requires reinforcing the scope of research in the field of the type of intervention and the impact of these new leaders on the general population. Similarly, the universalization of Internet access has led to greater concern on the part of political parties and their candidates to ensure a more effective presence on digital platforms, finding a new space to recover the importance of the political message and the connection with the electorate (Bimber and Davis, 2003). The alternative to traditional media allows political actors to challenge the rigidity of the political and media system, in a process that significantly changes the campaign strategy.

1 Article translated by Carolina Peralta. 
The growing interest in the analysis of digital electoral campaigns stems, precisely, from the engagement they provide, as well as the possibility of ensuring an inverse communication (bottom-up) from the electorate. This influences the discourse and the proposals presented by political actors. In this sense, Gunn Enli and Eli Skogerbø (2013) identify three central reasons for using social networks: marketing, mobilization and direct contact with voters. The latter is more evident in political systems centred on the image and action of the candidates, when there is strong personalization of the campaign (Gunn Enli and Eli Skogerbø, 2013: 758). In this growing media space, social media provide the tools that candidates need to assert themselves with the electorate, dispensing with or, at least, relegating the role of traditional media to a secondary level. This new centrality of digital communication and the mechanisms of continuous interaction between political agents and the electorate represents a new functionality to ensure the involvement of citizens in the political dispute (Carlisle and Patton, 2013). This impact was evident in the election campaigns of Barack Obama (2008 and 2012), generating mass involvement through simple and effective messages (Bode, 2012). Social media, more specifically Facebook and Twitter, "mark a new environment and a new form of communication with citizens and organizations in a multidirectional way, but with the commitment to interact, that is, to be a proactive user in virtual communities" (Túñez and Sixto, 2011: 1).

The advent of the Trump presidency (2017-2021) marks a relevant period of analysis of the use of social media, whether in terms of studying the content of the message sent, or in terms of civic engagement and comparative studies resorting to the social media used by other political leaders. One notices a greater appeal to emotion on the part of the Republican candidate, as well as a more intensive use of these communication tools for the affirmation of identity values (Costa and Khudoliy, 2019).

This new communication model appears as an alternative to the traditional media, in a direct call to emotion and contact with each user, allowing meaningful interaction, either with the candidate, or with thousands of followers.

In fact, the victory of Donald Trump in the presidential elections of the US in 2016 was characterised by a significant use of social media, which became an instrument of communication with the electorate and of support around the candidate. This fact was amplified by the high number of Trump followers on the various social platforms (Azari, 2016). In this sense, this paper aims to analyse the way Trump used the Facebook platform during the election campaign period in the 2020 elections.

This paper focuses on three core objectives: to understand the importance of the impact of the digitization of information in electoral campaigns; to analyse how Donald Trump used Facebook to convey his message; and to examine the impact of these messages on his followers.

The speed of the transmission of information is a challenge in any scientific analysis. We need to check the scope of the communication, the meaning of the words/expressions used, and to understand the existing interaction dynamics, in order to contribute to the study and understanding of the success or failure of an 
electoral campaign. In fact, are we faced with an increasing role of the media and digital platforms for the electoral success or failure of a certain candidate or party?

Will we move towards an excess of personalization, in a process focused on the candidate at the expense of the proposals presented? This paper aims to contribute to the studies that link political communication, the use of social media and the handling of electoral campaigns, in an alternative process to in-person electoral campaigns.

\section{Political communication and social media}

There is growing debate about the impact and the typology of political communication expressed in social media, with this new communication model constituting an effective way of bringing together candidates and voters. The opening of an "unlimited" stage for citizens to express their opinions represents a direct mechanism for political participation, challenging traditional conceptions of participation. In fact, we can understand political participation as "the set of acts and attitudes that aim to influence, more or less directly and more or less legally, the decisions of those in power in the political system" (Pasquino, 2005: 50). However, involvement in social media implies a less conventional and less controlled model of participation by political actors. The proliferation of digital communication has eliminated intermediaries between political actors and citizens, which has advantages and disadvantages.

The greater possibility for intervention and the direct participation of citizens in the public debate may constitute valid alternatives for participation and constitute a new form of "control" of the action of public authorities, with the possibility of including social groups that were previously excluded in this debate. However, the quality of the debate can be affected by a wealth of information, which is difficult for all stakeholders to process. There is also the risk that political actors act in the face of social/media pressure at the expense of action based on reason (Dader, 2001 and Sampietro and Ordaz, 2015).

In addressing the political communication aspect, we are aware of the vast field of research in this field. Our approach reflects the concern to reconcile the scope of political communication in the field of social media in a specific context, the US presidential elections in 2020.

The personalization of the campaign, centred in a two-party context and involving an immediate choice between two governance options, reinforces the need to analyse the context of the electoral campaign and the message conveyed. The option to address the political communication associated with Donald Trump results from the impact of the Republican candidate on social media, as well as the fact that he uses digital platforms as an alternative to traditional media, in a path initiated in the first candidacy in 2016 (Azari, 2016). We bring together two central concepts, "communication" and "politics", bearing in mind that the democratic debate implies a way of conveying the message, this being facilitated and leveraged by the immediate access to information. The proliferation of social media and universal access to the Internet increasingly questions the role of 
traditional media, but it offers an opportunity to deepen the relationship between candidates and voters.

We do not advocate the view that this substitution automatically corresponds to a reinforcement of communication or improvement of the democratic goals of a given country. We are aware of the importance of traditional communication for the functioning of democracy, and of the possibility of the proliferation of online communication to generate the increase in fake news" (Pepp, Michaelson and Sterken, 2019). This increase was evident during the electoral debates in the 2016 US presidential election (Farkas and Schou, 2018).

The weight of the political message must be measured according to its scope. Its presence on social media provides a broad set of indicators of the reach of each post. This analysis should be carried out in the context of the use of social media, and the interpretation should not be automatically extrapolated to electoral results.

In a comprehensive way, and using Mcnair's (1999) contribution, we can identify three central elements of political communication: the media, political organizations, where political representatives are included, and citizens. These elements are in constant interaction and the system is conditioned by permanent feedback, with the content of the message producing a volume of interactions between the different actors in the communication process. However, the reach and power of social media go beyond this triple analysis by allowing a more direct, regular communication free from a set of constraints, namely the issue of the "selective participation filter".

However, some studies indicate that the use of communication via Facebook is not so different from the behaviours that individuals have in offline communication. The individual's action is not marked by the creation of a "virtual character" distinct from political involvement in a face-to-face environment (Miller, Bobkowski e Maliniak, 2015). The biggest difference lies in the number of interactions recorded on social media, making the impact of each message less visible or perceptible in a more global approach.

In a context in which there is exponential growth of social media and online communication, there is a path that ensures the creation of differentiated content and maintaining a level of permanent public discussion. In this domain, the Facebook platform "has emerged as an important political portal in North America and in a more global context" (Elmer, McKelvey and Devereaux, 2009: 416), ensuring, since 2008, a set of partnerships with traditional media in electoral periods.

Another path that must be followed in the analysis of this topic is the ability of social media to shape and condition the view of public opinion. With a high level of interaction, will it be possible to find patterns of communication and understanding between users of social media? Or are we looking at platforms that validate previous ideas that individuals have about certain parties or candidates?

We cannot fail to mention the importance of analysing the "play on emotions" and the ability to achieve significant user involvement with the candidate through 
messages, images or videos, as part of a communication strategy based on the appeal to the sentiment or the defence of moral and identity values. This "play on emotions" is decisive for the construction of group identity, whether in the context of defending the values and positioning of the candidate, or in attacking the opponent's candidacy (Sampietro and Ordaz, 2015). This analysis of a discourse that appeals to emotion or the adoption of a discourse based on rationality produce different contents and impacts, the option of each candidate/political actor being consistent with the campaign objectives.

The critical look at Donald Trump's actions on social media, specifically on Facebook, results from the very organization and dynamics of the functioning of international decision centres and the posture of the 45th President of the US. Donald Trump's leadership promoted the affirmation of a populist, antiglobalization and protectionist agenda, triggering a succession of significant cultural events and confrontations (Inglehart e Norris, 2016 e Mayda e Peri, 2017).

This intervention dynamism was fuelled by Trump's strong presence on social media, namely on Facebook and Twitter, ensuring a considerable civic engagement in these domains (Ott, 2017 and Ross and Caldwell, 2020). It is important to highlight that this presence was more evident in periods of electoral competition. Still, the use of digital platforms of the fact checking model and verification of the veracity of the information can question the exposed contents, reducing or mitigating the message's impact.

The importance of observing the relationship of political communication within the scope of social media is core in the analysis of current electoral campaigns. The change in the traditional model of communication with the electorate and the involvement of thousands of citizens in the public debate produce significant changes in the theoretical models of analysis of campaigns and electoral results, with the inclusion of a set of variables and indicators in this analysis.

\section{Research design, methodology and data collection}

This research focused on the analysis of the political communication of Donald Trump on Facebook immediately before the US presidential elections in 2020 (held on 3 November 2020). The research design makes it possible to ask a central research question: what was the communication model adopted by Trump in the period before the presidential election? Likewise, we resort to two derived questions to deepen the analysis: what were the characteristics and elements used in the candidate's publications as a whole? What was the impact of the publications on the followers of Trump's official page?

In the vast literature we identify two relevant paths: studies that focus on the influence and impact of the media on electoral results and the functioning of democracy (Ansolabehere, Behr and Ivengar, 1991; Graber 2004 and Lange and Ward, 2004) and empirical studies focusing on the impact of social media and communication models associated with everyday political life (Elmer, McKelvey and Devereaux, 2009; Farkas and Schou, 2018; Thorson, Cotter, Medeiros and Pak, 2019; Ross and Caldwell, 2020; Linden, Panagopoulos and Roozenbeek, 2020). 
We chose the second path as it allows to decode the communication codes associated with Trump's strategy in an attempt to ensure his re-election, as well as to gauge the impact of each publication on the network of followers. The option for Facebook is justified by the number of followers that the candidate has (more than 35 million followers on 3 November 2020), as well as by the dimension of the platform, widely disseminated and recognized in the context of digital platforms ${ }^{2}$.

The study uses content analysis of publications on Donald Trump's official Facebook page, from 1 October 2020 to 3 November 2020. All publications from the month before the elections, as well as the days in November prior to this election, were aggregated. It should be noted that the electoral process is continuous, with a record amount of early votes registered in these elections ${ }^{3}$.

This approach allows us to know what kind of topics were included and to analyse the impact (reactions) to each post, enabling interpreting Trump's communication and electoral strategy.

From a methodological point of view, the research focused on content analysis. It used the quantitative and qualitative approach, with a category basis, and considered the number of publications and their typology. The use of content analysis is in line with studies on the analysis of messages published on social media and the approach to the online political communication strategy.

In addition to content analysis, we used the semiotic communication model in the same way, with the aim of analysing and understanding the meaning of the messages of the Republican candidate in the period preceding the electoral act.

This approach is in line with the contributions of Berelson (1952), Bardin (1977) and Krippendorf (2004), with a special focus on the descriptive analysis of the content expressed in the media (Semetko, and Valkenburg, 2016 ). This strategy corresponds to a classic approach to the use of this research technique, combined with its adaptation through the specificity of the phenomena to be observed, associating a quantitative aspect with a qualitative aspect with a category and inferential basis.

During the selection of the number of messages, we framed the study in an analysis model composed of six categories and respective variables: William Benoit's political discourse functional theory (acclaiming; attacking; defending); Aristotelian rhetoric; (logic; customs; emotion); the action request (donation; vote; involvement); the topics covered; the structure of the publication (video, image, text, hyperlink) and the impact of the publication (number of reactions, shares and comments).

2 Facebook is the most used digital platform/social media in the world. In: https://datareportal.com/socialmedia-users, accessed on 10 January 2021.

3 Over 100 million voters voted in advance, removing a significant impact from the face-to-face vote on 3 November 2020 In: https://www.nytimes.com/2020/11/02/us/politics/a-staggering-100-millionamericans-voted-early-suggesting-a-record-turnout.html, accessed on 12 January 2021. 
Table 1. Analysis Model

\begin{tabular}{|c|c|}
\hline Categories & Variables \\
\hline \multirow{3}{*}{ Benoit's Functional Theory } & Acclaiming \\
\hline & Atacking \\
\hline & Defending \\
\hline \multirow{3}{*}{ Aristotelian Rhetoric } & Logic \\
\hline & Customs \\
\hline & Emotion \\
\hline \multirow{3}{*}{ Action Request } & Donation \\
\hline & Vote \\
\hline & Support/Involvement \\
\hline \multicolumn{2}{|l|}{ Topics Covered } \\
\hline \multirow{4}{*}{ Structure of Publication } & Video \\
\hline & Image \\
\hline & Text \\
\hline & Hyperlink \\
\hline \multirow{3}{*}{ Impact of Publication } & Reactions \\
\hline & Shares \\
\hline & Comments \\
\hline
\end{tabular}

This analysis model allows us to take a global and comprehensive approach to communication strategies, as well as Trump's options in using this social network. In a schematic way, it should be noted that the functional analysis theory has been regularly used to analyse electoral debates and the various contents of political communication (Benoit et al., 2002). The objective is to structure the type of campaign and language used according to the aspirations of each candidate.

In a second segment of analysis, we framed the publications according to Aristotle's rhetorical art, structuring registered publications as "appealing" to logic, emotion, customs or traditions (Rohden, 1997). In a third segment, we structured the publications according to the action request, which may involve a request for donations, a call to vote or a request for support/involvement in the campaign. The analysis also focuses on the core campaign topics exposed in each of the publications in the period under study. The fifth and sixth segments deal with the format of the publication (text, video, image or use of hyperlinks) and the respective impact, considering the number of shares, the comments generated and the number of reactions.

The data is organized based on this category framework. The central objective was to address the communicational intentionality associated with each publication in this social media. The use of content analysis and the semiotic model of communication allows to group the collected information and structure the contents in processes of codification, categorization and inference (Espírito Santo, 2008). The selected model starts from a set of predefined variables, in order to frame the publications registered in that analysis. 


\section{Corpus Analysis}

This paper examined the period between 1 October 2020 and 3 November 2020. It studied the publications in the official account of Donald Trump on Facebook in the period immediately prior to the Presidential elections, also characterized by a high record of early voting (by mail and in person).

A total of 215 publications made in 34 days (average of 6.3 publications per day) were extracted and analysed using the NodeXLGraph software. The categorization process thus ensures the conditions for the scientific validation of the time and thematic cut-off of this study, in a process based on the objectivity of the information and the adequacy of the methodology to the studied contents (Bardin, 1977).

\section{Results}

The analysis of the data collected took into account a set of a priori conditions: the publications occur in the middle of the electoral campaign period, but simultaneously in the process of voting, given the size of the early vote in the last North American elections. The publications appear on President Donald Trump's official Facebook account (https://www.facebook.com/DonaldTrump) and were collected the day after the elections (4 November 2020). The fact that the United States' political system is strongly marked by a dichotomous, two-party perspective, which increases the polarization of the political debate, must be highlighted.

\section{Functional theory of political discourse}

The functional theory model is directly related to the communication strategy of each candidate and to the potential associated with each communication platform, in this case social media (Facebook). The model determines the classification of publications in three dimensions: submission of proposals (legislative/thematic) or announcements of the candidate's acclaim; attack speeches (to opponents, other actors involved in the electoral debate or other institutions) or defence speeches (in the face of previously confirmed attacks).

It should be noted that this analysis takes into account the number of publications $(n=$ 215), but several publications combine acclaim, attack and defence content, as seen in the other categories. The same publication may contain elements that allow framing it in multiple variables. It should be noted that more than half of the contents corresponded to acclaim messages from the candidate or presentation of political proposals, despite being of a general scope, that is, of proposition in relation to certain topics or demonstration of intentions in public policies. 
Chart 1. Theory of functional analysis of political discourse

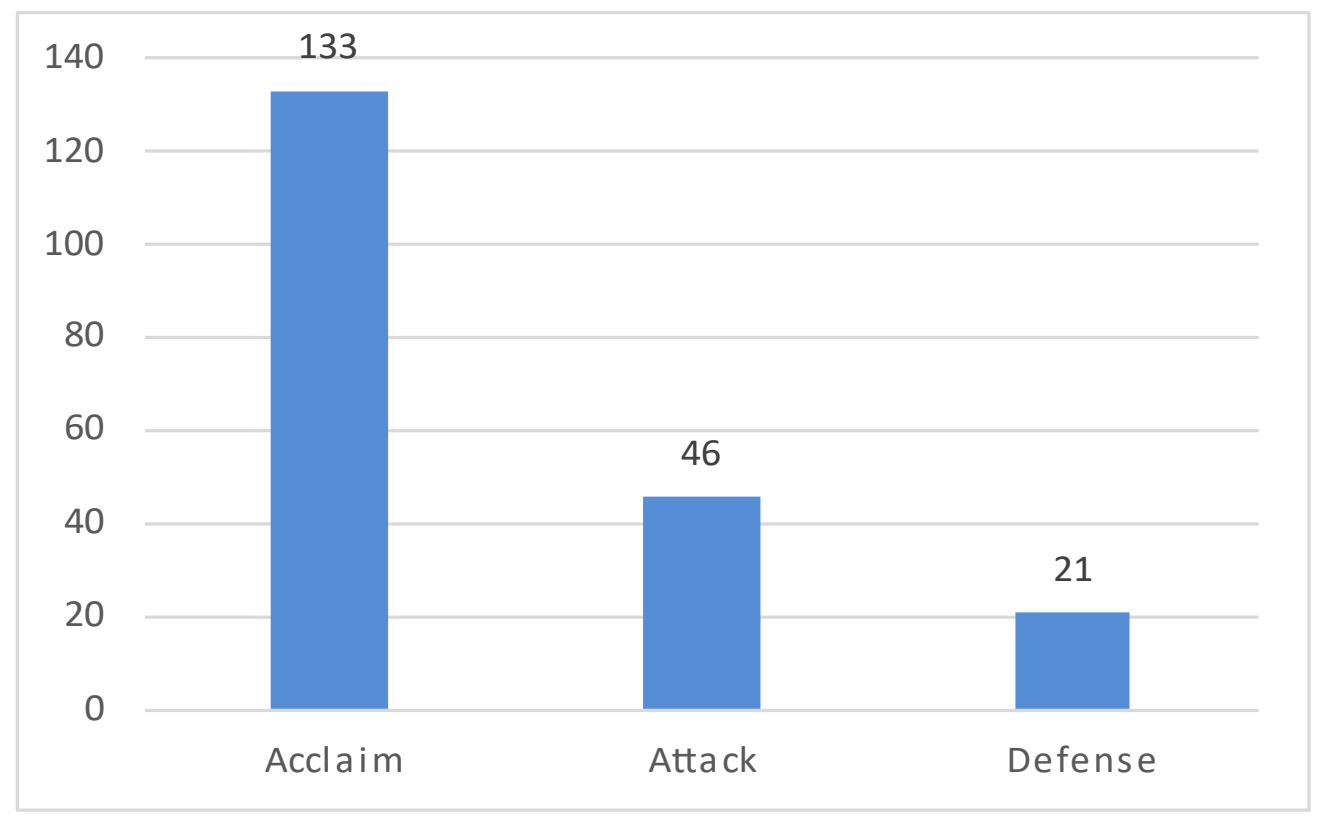

This approach also reflects the fact that this acclamation was made with the systematic use of the broadcast of Trump and Mike Pence rallies live on Facebook ( 79 publications, that is, $37 \%$ of all publications). In turn, there is a considerable number $(21 \%)$ of publications that substantiate attacks, namely on the Democratic candidate, Joe Biden, and on the media. The attacks are dispersed, involving Joe Biden's tax plan, measures on the legalization of immigrants, the reinforcement of lockdown due to the health pandemic or the attack on the media by disclosing certain electoral polls.

\section{Aristotelian Rhetoric}

In the political discourse analysis model presented on Facebook, the publications fit into three types of discourse, according to the Aristotelian rhetoric model. There is an interpretation of these contents in the light of the defence and promotion of logical reasoning based on the evidence or data presented, a second model of communication based on the valuing or presentation of North American customs or traditions and a third model of communication based on emotion and the direct involvement of users with their candidate. 
Chart 2. Language model according to Aristotelian rhetoric

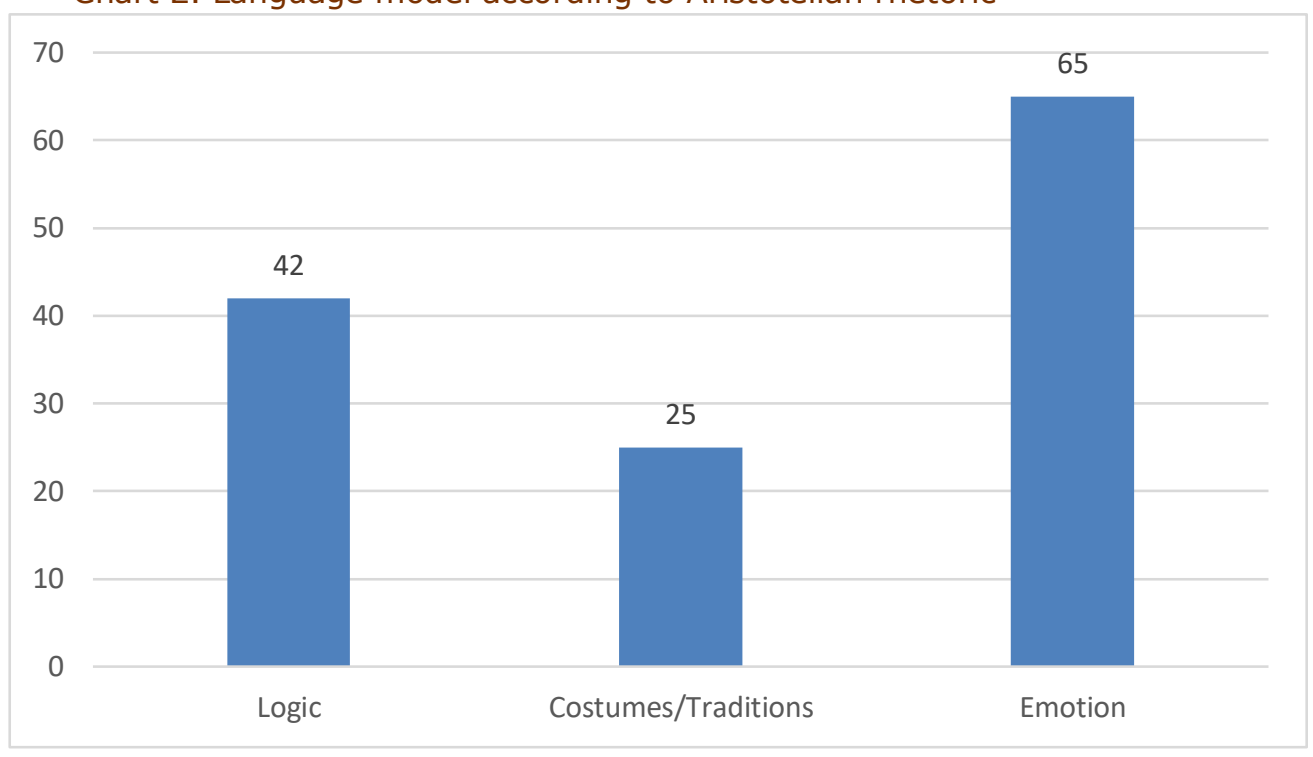

In this regard, mention should be made of the primacy given to emotional speeches/ content, calling for a reinforcement or a deepening of the symbiosis between Trump supporters and the Republican candidate. These contents reflect a message of "struggle" on behalf of the candidate and on behalf of the country. There is also regular use of positive adjectives by American citizens (ex: "proud", "great") and the dissemination of Trump images surrounded by crowds of supporters, creating a population "support" for the Republican Party campaign.

\section{Action Request}

Political communication is often based on a direct request for support or involvement from users (voters) in the electoral campaign. When examining the publications during this period, we checked if there were any requests for donations, traditional in North American campaigns, any direct or indirect call to vote and calls for support and involvement in campaign actions.

From the data analysis, despite the strong investment required to launch a presidential campaign in the US, there is only one publication related to requests for or references to donations, which may be related to the fact that the analysis focuses on the final part of the electoral campaign. 
Chart 3. Action requests

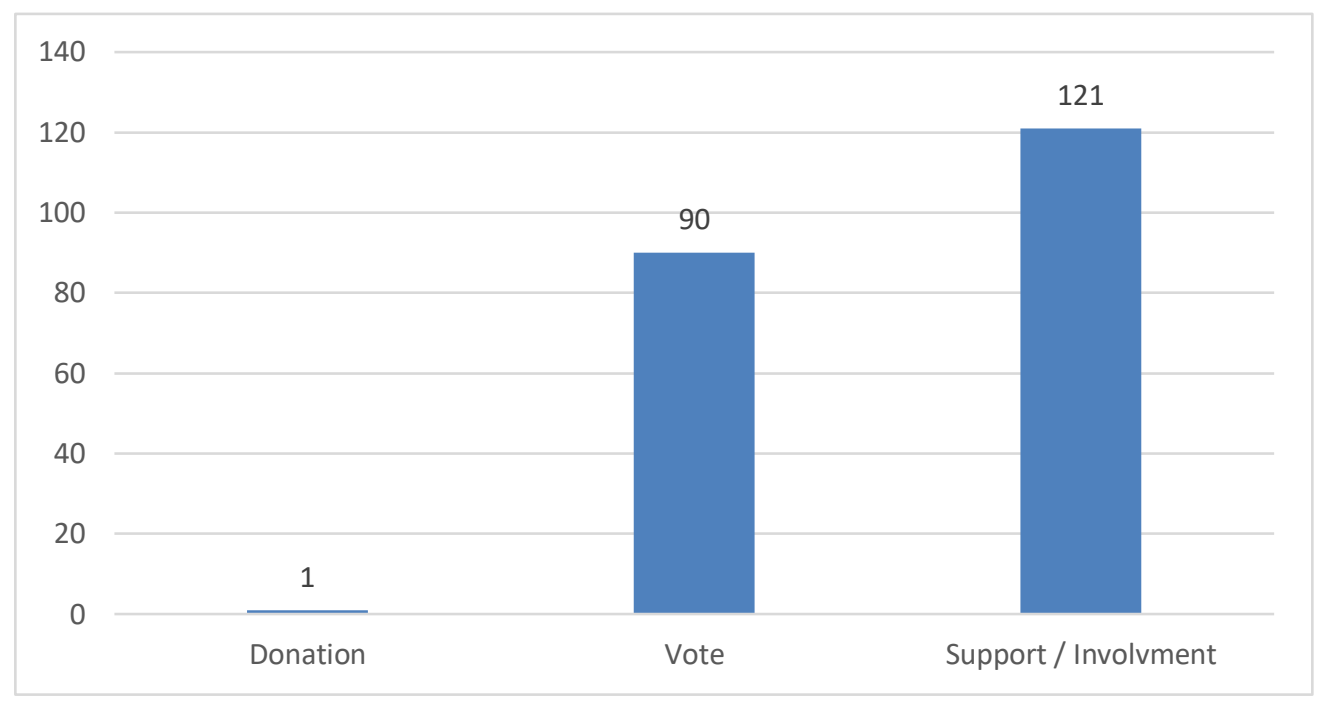

The communication was based on calls for direct involvement in campaign actions (in person or online) and direct references to voting, namely with the creation of an incentive for users to send a message to a campaign number with the word "vote". This allowed the campaign team to create a wide network of contacts/database of potential voters. Thus, the requested involvement focused on creating greater monitoring of online initiatives (engagement on social networks) or requesting a direct call to vote.

\section{Topics Covered}

In this category, we chose to identify the topics covered in each publication, creating a thematic "script" of Trump's communication structure. From the analysis carried out, there is a significant diversity of contents, and it is not possible to unveil a coherent thematic line of action during this period.

Table 2. Main topics covered

\begin{tabular}{|c|c|c|c|c|c|c|c|}
\hline \multicolumn{8}{|c|}{ Topics } \\
\hline Economy & Media & Religion & Covid & Polls & Health & Industry & Energy \\
\hline 21 & 7 & 6 & 6 & 6 & 4 & 4 & 3 \\
\hline
\end{tabular}

In the middle of a pandemic, in terms of communication priority was given to economic issues, precisely the aspect where Trump sought to capitalize his action in the White House, namely with emphasis given to economic indicators and the recovery period experienced after the second half of 2020. These contents were strongly related to publications associated with the industry and energy sector and job promotion in the country. 
Also worthy of note is the regular reference to the media and polls, in a strategy of playing down and attack the media during the campaign, as well as the broadcast of religious content (live prayers on Facebook), in a direct appeal to the catholic and evangelical vote.

The references to Covid-19 were made in order to defend the testing capacity of the US and to attack the possibility of promoting the closure of services or economic activity. It was a topic with little impact on the communication dynamics on Facebook.

\section{Publication Structure}

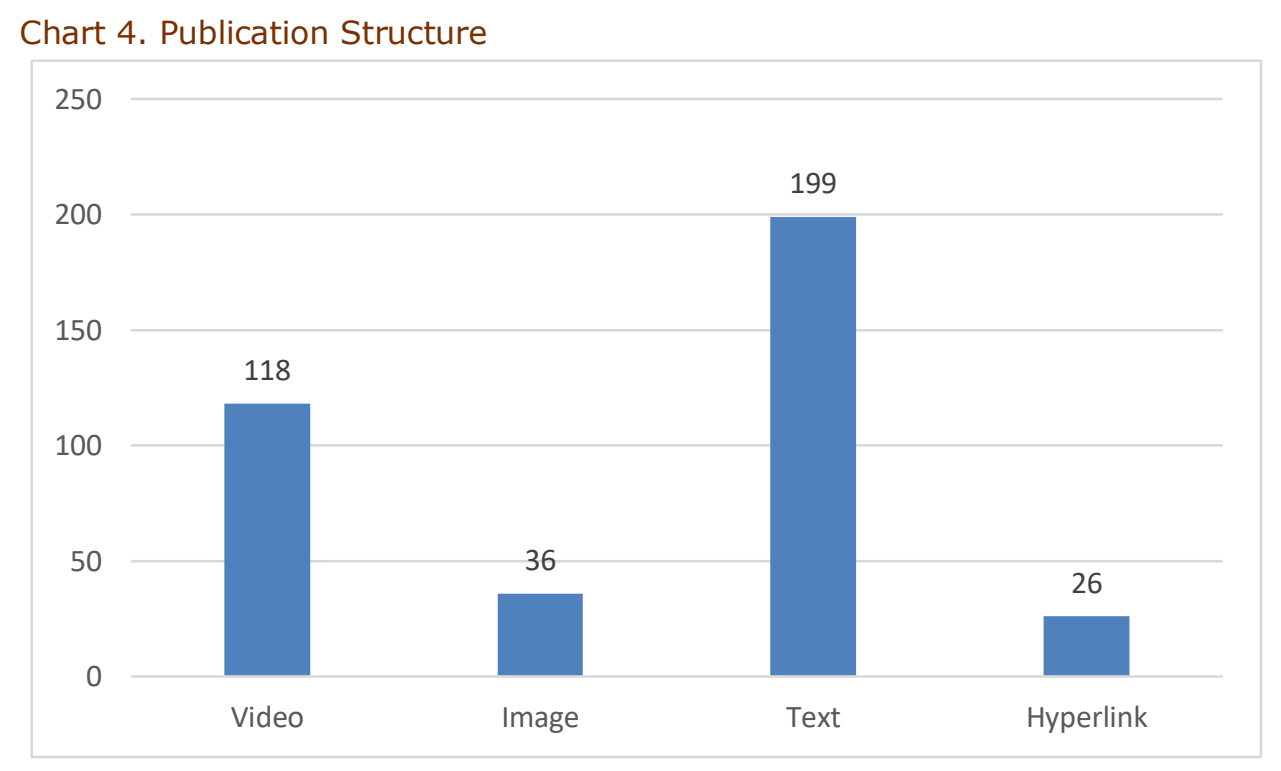

Almost all publications had at least two formats, the most recurrent being text communication. Alongside this option, there was live broadcast of several campaign events, including rallies by Donald Trump and Mike Pence, as well as the broadcast of some programmes by Trump's campaign team. The regular publication of videos (live or recorded) allowed greater user engagement and the establishment of synchronous comments, in a process of systematic politicization of the shared content. Less usual was the use of hyperlinks, which corresponds to the objective of directly publishing information without the need to "force" users to access other electronic addresses. This option, of simultaneous use of video and image alongside the text, attests the effectiveness of the image and the permanent interaction in the live content. The power of the image was decisive for the effectiveness of the political message and for inviting the reactions of users.

\section{Publication Impact}

With regard to the impact of publications, the number of reactions, shares and comments that each publication triggered were analysed. It also enabled seeing the contents that generated greater adherence on the part of users. 
Chart 5. Impact (average of reactions, shares and comments)

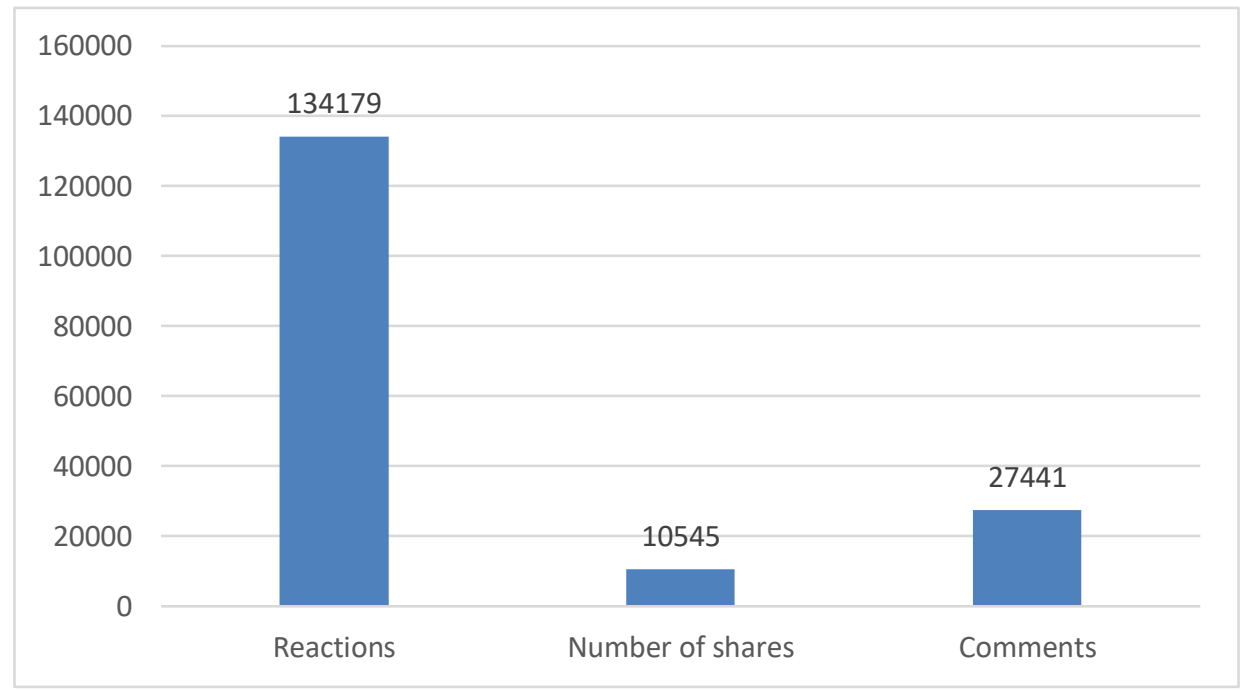

The figures reflect a significant dynamic of Trump's official website, with a disparity in the impact of each publication. Graph 5. shows the averages of the number of reactions, shares and comments, but it is important to check the content that produced the most impact, paving the way for greater understanding of the content with the greatest impact.

Regarding the sharing of publications, the most shared content was a cover of the "New York Post" newspaper, with a quote from the American rapper 50 Cent, with the statement "I don't want to end up 20 cent", in a criticism of the tax plan defended by Joe Biden. This publication was shared by 162,000 users. The second publication with the highest number of shares $(118,000)$ was the release of a video with images of Donald Trump and Joe Biden rallies, with the first recording a considerable crowd and the second having a small number of participants, due to the campaign strategy adopted in times of pandemic. The third most shared publication $(104,000)$ was a video of a set of Trump supporters "escorting" a Joe Biden campaign bus in the State of Texas, with the video's description: "I love Texas".

In terms of comments, the publications with the greatest impact were the presidential debate between Trump and Biden, which was broadcast live on 23 October 2020, with a total of more than 290,000 comments; the final campaign message, written on 3 November, had a total of 224,000 comments and reflected Trump's thanks to his supporters ("To all our supporters: thank you from the bottom of my heart. You have been there from the beginning, and I will never let you down. Your hopes are my hopes, your dreams are my dreams, and your future is what I am fighting for every single day") and the debate between the two vice president candidates, Mike Pence and Kamala Harris, on 18 October 2020 (118,000 comments).

In terms of the typology of reactions, we opted for a global approach, taking into account that most of the reactions were positive (like "like" or "love"). The publication with the highest number of reactions was precisely the final campaign acknowledgment text set out above, with a total of $1.515,469$ reactions (more than $98 \%$ of the reactions were 
positive). The second publication with the greatest impact was Trump's statement after recovering from Covid-19, on 6 October when he wrote on the platform a short text stating that he felt great. This publication generated a total of $1.476,929$ reactions (more than $96.6 \%$ positive reactions). The other publications with the greatest impact addressed the issue of education (approval of legislation to prevent indoctrination in schools), with a total of 803,000 reactions and the transmission of the campaign motto adopted in 2016 and replicated in 2020 "Make America Great Again", with a total of 745,000 reactions.

Simple messages were more successful and there was greater dynamism of social media with live content, promoting greater participation of followers of Trump's official page. Thus, the use of a direct communication model was confirmed, using the publication of face-to-face events on Facebook and content to promote user involvement and participation dynamics in campaign actions. The option lied in content linked to appreciation and promotion of Trump, as well as the use of content promoting sentimental/emotional links around the candidacy.

From a strategic point of view, there was regular use of messages to attack political opponents and the media, using a combination of text and video publications. A significant variety of topics were covered, with emphasis on economic issues. The official page records a significant level of engagement, with thousands of comments, shares and reactions. The content was simpler and more objective, along with the broadcast of campaign debates, which provoked a higher level of reaction on the part of users.

Although Trump was defeated in the elections, this level of enthusiasm and presence on social media may be associated with an improvement in the vote compared to 2016 (Trump got 10 million more votes in 2020 than in the first election), as well as a more competitive performance compared to the forecast of electoral studies.

\section{Conclusions}

The research around the strategic communication options of political leaders directly intertwines with the analysis of the electoral results and with the voters' perception of the charisma and action of each political actor. Although the importance of analysing the impact of physical presence, namely the role of candidates in electoral debates or at rallies, continues to be confirmed, the proliferation of social media and their daily use by voters indicates the need to examine their use for political purposes, both by political actors (message senders) and users (message recipients).

This research enabled understanding Donald Trump's campaign strategy regarding the use of Facebook, as well as analysing the engagement of its users, in a period strongly marked by political and social instability in the US due to political polarization and strong electoral mobilization.

The analysis of electoral campaigns implies a multidisciplinary view and a critical stance at the multiple variables that influence voters' behaviour and their perception of candidates and the central topics in the decision-making process regarding the vote. The use of social media represents one of the paths of this research process, considering the growing access to these platforms and the progressive replacement of institutional communication with daily communication on social media. 
The advent of online communication adapted to political content opens the opportunity to broaden electoral studies, as well as theories to explain voters' behaviour. In this context, the reasons associated with the use of social media (marketing, mobilization and direct contact) are part of the strategy and the path followed by the Republican candidate.

By focusing the analysis on the publications made in the period immediately prior to the election, we were able to unveil political communication in the most intense phase of the campaign on Facebook, where Trump has the largest number of followers.

The data presented allow us to characterize Trump's strategy on Facebook. His presence was marked by the publication of several daily messages and the use of a simple, objective and focused discourse in an attempt to ensure the immediate adhesion of users to his political message. Likewise, the analysis of this social media shows the impact and importance of social media in the campaign strategy, ensuring the creation of a wave of enthusiasm around the candidacy, in a period when the face-to-face events decreased due to the pandemic.

The communication processes during the electoral campaign period focused on topics that reflected the voters' concerns. However, this does not mean an immediate adhesion of the candidate to a hierarchy of topics presented or defended by the electorate. The discourse was centred on Trump's political agenda and his objectives of attacking the proposals presented by Joe Biden. This process determines the need to deepen the research around the content expressed in each publication and in the associated comments, allowing future research (causal relations) between communication and the users' perception of the various topics addressed.

In a context of significant growth in the use and potential of online communication, it is important to deepen the study of the means, techniques and strategies used to promote political participation, opening up a range of opportunities for public discussion outside the traditional channels of debate. The partisanship and polarization of social media are one of the most relevant objects of study in the near future, in a rediscovery of forms of communication and in an analysis of the dimension and reach of the digital platforms on politics. With this study we seek to map future analyses on the relationship between the media and politics, based on the theoretical articulation between communication and political science.

\section{References}

Ansolabehere, S., Behr, R., \& Iyengar, S. (1991). Mass Media and Elections: An Overview. American Politics Quarterly, 19(1), 109-139.

Azari, J. (2016). How the news media helped to nominate Trump. Political Communication, 33(4), 677-680.

Bardin, L. (1977). Análise de conteúdo. Lisboa: Edições 70.

Benoit, W. L. et al. (2002). The primary decision: A functional analysis of debates in presidential primaries. Westport, CT: Praeger. 
Berelson, B. (1952). Content analysis in communication research. New York: The Free Press.

Bimber, B., \& Davis, R. (2003). Campaigning Online: The Internet in U.S. Elections. New York: Oxford University Press.

Bode, L. (2012). Facebooking it to the polls: A Study In Online Social Networking And Political Behavior. Journal of Information Technology \& Politics, 9(4), 352-369.

Carlisle, J. E., \& Patton, R. C. (2013). Is social media Changing How We Understand Political Engagement? An Analysis of Facebook and the 2008 Presidential Election. Political Research Quarterly, 66 (4), 883-895.

Cooper, M. (2020, November 2). 100 million Americans voted early suggesting a record turnout. New York Times. Available at: https://www.nytimes.com/2020/11/02/us/politics/a-staggering-100-million-americansvoted-early-suggesting-a-record-turnout.html

Costa, B. F. \& Khudoliy, A. O. (2019). The relevance of public speech in the presidency of Donald Trump - The US elections in analysis. Estudos em Comunicação, 29, 103-126.

Dader, J. L. (2001). La ciberdemocracia posible: reflexión prospectiva a partir de la experiencia en España. Cuardernos de Informácion y Comunicación (CIC), 6, 177-220.

Data Report. (s/d). Social Media Users. (2021, January 10). Available at: https://datareportal.com/social-media-users.

Elmer, G., McKelvey, F \& Devereaux, Z. (2009). Networked publics: the double articulation of code and politics on Facebook. Canadian Journal of Communication, 34, 415-434.

Espírito Santo, P. (2008). Estudos de Comunicação Política. Análise de Conteúdo da Mensagem na Campanha e Pós-Campanha eleitoral nas Eleições Presidenciais. Lisboa: ISCSP.

Farkas, J. \& Schou, J. (2018). Fake News as a Floating Signifier: Hegemony, Antagonism and the Politics of Falsehood. Javnost - The Public, 25(3), 298-314.

Gunn, S. E. \& Skogerbø, E. (2013). Personalized campaigns in Party-centred politics. Information, Communication \& Society,16(5), 757-774.

Graber, D. (2004). Mediated politics and citizenship in the twenty-first century. Annual Review of Psychology, 55, 545-571.

Inglehart, R. F. \& Norris, P. (2016). Trump, Brexit, and the Rise of Populism: Economic Have-Nots and Cultural Backlash. HKS Working Paper No RWP16-026. (2020, December 12). http://dx.doi.org/10.2139/ssrn.2818659

Krippendorff, K. (2004). Content analysis: An introduction to its methodology. Thousand Oaks, CA: Sage.

Lange, B.P. \& Ward, D. (2004). The media and elections: a handbook and comparative study. London: Routledge.

Linden, S., Panagopoulos, C. \& Roozenbeek, J. (2020). You are fake news: political bias in perceptions of fake news. Media, Culture \& Society, 42(3), 460-470. 
Mayda, M. \& Peri, G. (2017). The economic impacto US immigration policies in the Age of Trump. In C. Bown (ed.). Economics and Policy in the Age of Trump. London: CEPR Press Centre for Economic Policy Research.

Mcnair, B. (1999). An introduction to political communication. London: Routledge.

Miller, P., Bobkowski, P. \& Maliniak, D. (2015). Talking politics on Facebook: network centrality and political discussion practices in social media. Political Research Quarterly. 68(2): 377-391.

Ott, B. L. (2017). The age of Twitter: Donald J. trump and the politics of debasement. Critical Studies in Media Communication, 34(1), 59-68.

Pasquino, G. (2005). Curso de ciência política. Cascais: Principia.

Pepp, J., Michaelson, E., \& Sterken, R. K. (2019). What's New About Fake News? Journal of Ethics and Social Philosophy, XVI (2), 67-94.

Rohden, L. (1997). O poder da linguagem: a arte retórica de Aristóteles. Rio de Janeiro: EDIPUC-RS.

Ross, A. S. \& Caldwell, Dd. (2020). Going negative: an appraisal analysis of the rhetoric of Donald Trump on Twitter. Language \& Communication, 70, 13-27.

Sampietro, A. \& Ordaz, L. V. (2015). Emotional politics on facebook. An exploratory study of Podemos' discourse during the European election campaign 2014. RECERCA, Revista de Pensament I Anàlisi, 17, 61-83.

Semetko, H.A. \& Valkenburg, P.M. (2016). Framing European politics: a content analysis of press and television news. Journal of Communication, 50(2), 93-109.

Túñez, M. \& Sixto, J. (2011). Redes sociales, política y Compromiso 2.0: La comunicación de los diputados españoles en Facebook. Revista Latina de Comunicación Social, (66), 125.

Thorson, K., Cotter, K, Medeiros, M \& Pak, C. (2019). Algorithmic inference, political interest, and exposure to news and politics on Facebook. Information, Communication \& Society, 1-18, 283-200. 